\title{
De portas fechadas: a midiatização do fechamento das fronteiras venezuelanas com Brasil e Colômbia
}

\author{
Márcio Barbosa Norberto 1 \\ Ada Cristina Machado Silveira ${ }^{2}$ \\ Mayara Souto Collar3
}

Resumo

O artigo traça uma aproximação com a noção de midiatização na situação de cobertura noticiosa sobre a crise na fronteira entre Brasil, Colômbia e Venezuela em fevereiro de 2019. Trata-se de um recorte temporal da cobertura internacional, compreendendo o período considerado de maior tensão, quando do fechamento da fronteira pelas autoridades venezuelanas, momento em que o trabalho jornalístico se intensificou. O objetivo do estudo foi o de identificar o volume de notícias veiculadas por diversos veículos circulantes no Brasil, com foco no Portal de notícias G1/Norte/Roraima com vistas a avaliar em que medida o processo de midiatização influenciou a construção e difusão do acontecimento noticiosos.

Palavras-chave: Jornalismo internacional. Midiatização. Fronteira.

\section{Abstract}

The article draws an approximation with the notion of media coverage of the crisis on the border between Brazil, Colombia and Venezuela in February 2019. This is a temporal cut in international coverage, comprising the period considered to be the most tense, when the border was closed by the Venezuelan authorities, when the journalistic work intensified. The objective of the study was to identify the volume of news stories published by various vehicles circulating in Brazil, focusing on the G1 /

1 Doutorando em Comunicação (UFSM), mestre em Jornalismo pela Universidade Estadual de Ponta Grossa/PR, graduação em Comunicação Social com habilitação em Jornalismo pela Escola de Comunicação das Faculdades Integradas do Brasil - Unibrasil, Curitiba/PR, pós-graduação lato sensu em Gestão Cultural (Faculdade Senac/2011) e pós-graduação lato sensu em Comunicação, Cultura e Arte (PUC/PR/2008). E-mail: marciob.norberto@gmail.com.

2 Professora titular da Universidade Federal de Santa Maria, onde integra o quadro permanente do PPGComunicação, lidera do grupo de pesquisa Comunicação, identidades e fronteiras. É pesquisadora do CNPq e professora colaboradora no mestrado profissional em Comunicação e indústria criativa da Universidade Federal do Pampa, campus de São Borja. E-mail: adac.machadosilveira@gmail.com.

3 É bolsista de iniciação científica (Pibic-CNPq) do grupo de pesquisa Comunicação, identidades e fronteiras e aluna do curso de Jornalismo da Universidade Federal de Santa Maria. E-mail: mayarasoutoc@gmail.com.

Revista Pauta Geral-Estudos em Jornalismo, Ponta Grossa, vol. 6, n. 1, p. 39-58, Jan/Jun, 2019. 
Norte / Roraima News Portal, with a view to evaluating the extent to which the mediatization process influenced the construction and diffusion of the news event.

Keywords: International journalism. Midiatization. Border.

\section{Introdução}

O artigo tem por objetivo relatar uma análise realizada sobre a cobertura jornalística internacional do momento de crise na fronteira venezuelana com a Colômbia e o Brasil. A análise detém-se dentro de um pequeno recorte temporal. A escolha do recorte deu-se pelas tensões e mortes decorrentes da decisão de bloqueio por parte do governo venezuelano de Nicolás Maduro.

A intensidade dos acontecimentos e a elevação da temperatura chamaram a atenção do jornalismo para uma cobertura de proporção internacional. O referencial teórico do trabalho inicialmente percorre uma breve apresentação histórica acerca do jornalismo internacional, algumas de suas características e de que forma este fazer ajuda a estruturar os acontecimentos. $\mathrm{O}$ artigo perpassa ainda por aspectos relacionados à midiatização da cobertura e seu impacto nas características de construção da noticiabilidade.

O corpus empírico de análise apresenta inicialmente uma vista panorâmica sobre o período de sete dias do fechamento da fronteira venezuelana com o Brasil e, posteriormente, com a Colômbia em diversos veículos acessíveis sem pagamento desde o Brasil. Posteriormente, a análise aprofunda-se no portal de notícias G1 região norte e do estado de Roraima, entre os dias 22 e 24 de fevereiro de 2019. A coleta realizada levou em consideração os assuntos relacionados à crise e aos conflitos desencadeados nas fronteiras com a Venezuela. A abordagem metodológica adotada tem natureza quantitativa, pois se interessa pelo volume de material jornalístico publicado. No entanto, a partir deste corpus empírico, são realizadas algumas inferências descritivas e analíticas a fim de refletir sobre certas operações próprias da organização jornalística no processo de construção da notícia.

\section{Jornalismo internacional: correspondentes, enviados e agências}

Do ponto de vista histórico, identifica-se referências ao jornalismo internacional datando da segunda metade do século XIX. Segundo Monteros (2008, p. 51), "sua história está ligada ao desenvolvimento da escrita, à imprensa, à indústria editorial, às tecnologias de comunicação e ao transporte". É uma época de transição de um fazer jornalístico de 2019. 
natureza interpretativa e literária, com viés político, para um trabalho voltado ao fato cotidiano, sendo produzido com a característica de relato tal qual como se conhece hoje: noticiário informativo.

No início, as motivações e interesses pela cobertura internacional foram por assuntos relacionados à economia, por exemplo, os preços das commodities no mercado internacional. Monteros (2008) fala justamente sobre a difusão do preço de grãos no mercado norte-americano que eram produzidos em Londres. As primeiras agências de notícias criadas até o começo do século XIX tinham inicialmente a prerrogativa de distribuir informações relacionadas à questão econômica, com a difusão de notícias sobre agricultura e mineração. Segundo o autor, os assuntos econômicos configuraram-se na primeira matéria-prima das agências de notícias. Os temas relacionados a conflitos também eram de grande interesse e, conforme relato do autor, perduram até hoje.

A construção do relato noticioso sobre a realidade atualmente não mais ocorre de maneira unidirecional, ou seja, o veículo/agência de notícia sendo o detentor da produção e da difusão do conteúdo. O volume de indivíduos, envolvidos ou não nos acontecimentos que desejam reportar, também é atuante nesta visada. O processo de midiatização dos eventos, tanto pelos veículos de comunicação quanto pela sociedade mudou a forma de construir os relatos. Este movimento tem implicação na cobertura internacional e como ela se estrutura. Antes, porém, de adentrar neste modelo, cabe uma tentativa de definir ou pelo menos de situar o que vem a ser o jornalismo internacional e qual o perfil dos profissionais atuantes.

Dito maneira simples, entende-se que é o segmento ou a especialização que visa cobrir eventos para além da fronteira do país onde o veículo está instalado, mandando para as localidades onde se passam os acontecimentos repórteres especiais; o que nos dias de hoje ocorre bem menos em razão do investimento necessário e de outras possibilidades de se fazer cobertura jornalística internacional.

A despeito dos modelos para os quais a cobertura jornalística internacional caminha, cabe considerar que há veículos de imprensa que mantém pelo mundo escritórios e jornalistas, os chamados correspondentes internacionais. Estes jornalistas têm base fixa no país e fazem coberturas de eventos especiais e do cotidiano, na cidade, na região e, muitas vezes, em países vizinhos.

Há também as agências internacionais de notícias com escritórios sediados em algumas localidades do mundo. Elas produzem material jornalístico e distribuem aos Revista Pauta Geral-Estudos em Jornalismo, Ponta Grossa, vol. 6, n. 1, p. 39-58, Jan/Jun, 2019. 
jornais. Com as novas tecnologias da informação e da comunicação, o trabalho das agências foi significativamente facilitado. Em relação às agências, Clóvis Rossi (2008) chamava a atenção para este domínio em 1980:

As cinco agências que ditam os rumos do noticiário internacional são a francesa Agence France Presse (AFP), as norte-americanas United Press International (UPI) e Associated Press (AP), a inglesa Reuters, a italiana ANSA e a alemã DPA, às quais se poderia acrescentar a espanhola AFE, além de algumas menores, mas igualmente baseadas em países desenvolvidos (ROSSI, 2008, p. 14).

As agências internacionais acabam ocupando praticamente todo o espaço que os jornais destinam ao noticiário internacional. Ao se referir sobre uma pesquisa da época, Rossi comenta o assunto dizendo que no período de uma semana um jornal brasileiro de circulação nacional publicou em seu espaço destinado à cobertura internacional mais de $55 \%$ de notícias oriundas de material fornecido pelas agências citadas: "Somem-se outros $4,8 \%$ de outras fontes externas e verifica-se que o jornal paulista preencheu apenas $30 \%$ de sua informação internacional com material de seus jornalistas e colaboradores" (ROSSI, 2008, p. 14).

Outros pesquisadores corroboram com a verificação de que o conteúdo jornalístico internacional veiculado nos meios de comunicação nacional é proveniente, em sua maior parte, de agências internacionais que priorizam recortes para atender a interesses de leitores norte-americanos e europeus, cujo foco são os aspectos negativos do continente. Bomfim (2006) analisa dois tradicionais veículos da imprensa brasileira e destaca a forma como as nações do continente recebem informações sobre o país vizinho.

$\mathrm{Na}$ cobertura internacional existem os jornalistas colaboradores (chamados de stringers ou freelancers) aqueles que não têm vínculo empregatício com o veículo de comunicação, apenas prestam serviços eventuais. $O$ espaço de trabalho em âmbito internacional comumente é legado aos jornalistas mais experientes, com conhecimento consolidado no jornalismo e habilidade para enfrentar desafios, mas há jovens jornalistas interessados pelo trabalho no exterior.

Conforme descreve John Hohenberg (2008) há os profissionais mais jovens que também se dispõem na aventura de novos desafios, buscando se destacar com o intento de se tornarem correspondentes internacionais: "Como repórteres freelancers eles se 
juntam aos repórteres profissionais que representam as organizações noticiosas" (HOHENBERG, 2008, p. 27).

Para se chegar ao posto de correspondente internacional não há uma fórmula ou caminho totalmente exato. Entre os que alcançam a carreira no exterior há profissionais altamente qualificados, tendo participado de cursos especializados em grandes universidades, outros chegam pela promoção na carreira, ou ainda são testados pelos veículos aos quais estão vinculados.

Com base no breve histórico aqui sintetizado e características do jornalismo internacional já seria possível identificar que a cobertura neste âmbito é mais abrangente, dando conta de pautas diversas que envolvem assuntos da política, da economia, da cultura, do meio ambiente, entre outros temas do cotidiano. O correspondente ou enviado especial precisa, portanto, ter habilidade para falar e tentar explicar ao público sobre os mais diversos assuntos que estruturam determinada região.

\section{Midiatização, jornalismo e convergência}

O jornalismo como prática social, seja numa pequena ou grande localidade, ajuda a estruturar o dia a dia da sociedade com sua forma particular de construir relatos. Num contexto mais distante e com características diferentes como, por exemplo, uma área de fronteira internacional o fazer jornalístico também é uma dimensão estruturante da região, trazendo informação daquilo que não se tem participação direta.

Bomfim e Müller (2013) analisam, com base em diversos pesquisadores, a participação do jornalismo internacional na estruturação da realidade e como esta prática profissional foi também afetada pelo desenvolvimento de novas tecnologias, produzindo conexão direta entre diferentes partes do globo, alcançando audiências em pontos distantes, produção da informação de forma instantânea e convergência.

Observa-se, assim, outra lógica de realizar cobertura internacional, na qual o correspondente, o enviado especial ou o freelancer se utiliza de material de terceiros porque não tem, em algumas situações, a melhor imagem ou conteúdo para publicação, ou pelo fato deste terceiro estar dentro do acontecimento. Um processo que, na produção noticiosa em área internacional, tem relação direta também com limitação na apuração que recorre a conteúdos de agências e de outros meios, como jornalistas locais, imprensa local e porque não dizer da própria população que faz circular em fluxo contínuo elevado número de informações, configurando um espaço midiatizado. 
Quando se diz que as formas de se comunicar e os fluxos comunicacionais mudaram, sobretudo nos últimos dez anos, não é uma constatação inusitada. As tecnologias propiciaram experiências diversificadas, com novos meios de produção, de circulação e de recepção, além do que alargaram o espectro de participantes nestes ambientes. Para bem ou para o mal, não se pode negligenciar que tudo ficou mais visível e invisível diante de tantas informações produzidas que ganham circulação e alcance à medida que os meios técnicos estão à disposição de todos.

No campo da comunicação jornalística, que absorve, reinventa-se e direciona, evidentemente, todas essas transformações, pensando em formas de alcançar e manter sua audiência frente às possibilidades comunicacionais, o relacionamento com a sociedade certamente não é mais o mesmo de uma década atrás.

Portanto, a forma de se relacionar entre campo midiático [consideramos aqui a comunicação jornalística] e sociedade foi profundamente alterada. Há uma série de atravessamentos de um lado ao outro, numa perspectiva de interação, de mediação e de reprodução das mensagens que Braga (2012, p. 31) vai tratar como "atravessamentos dos campos sociais estabelecidos, gerando situações indeterminadas e experimentações correlatas". Este processo tecnosocial chama-se midiatização.

Distando do objetivo de realizar uma cartografia sobre o conceito de midiatização, entende-se ser necessário este breve discorrer para operar sua relação ao objeto de discussão neste texto. A ideia sobre midiatização não se restringe a uma reflexão teórica fechada, com demarcação definida. Segundo Braga (2012, p. 36), "o conceito de midiatização ainda está em fase de construção".

Os investigadores costumam caracterizar a midiatização como processos que envolvem objetos distintos, como o próprio meio, os receptores, as mediações, entre outras elaborações técnicas. De acordo com Braga, o tema não está circunscrito tão somente às inovações tecnológicas à disposição e que os indivíduos fazem uso para as experiências mais diversas, do simples consumo à reflexão crítica. Braga observa que é necessário nesta visada um elemento diretamente social.

Para Martino (2012), o consenso sobre midiatização está longe de ser apaziguado. Numa perspectiva ampla, a ideia pode se assentar, segundo o autor, na direção das mudanças desencadeadas na sociedade contemporânea e que estão associadas ao desenvolvimento dos meios digitais de comunicação. Martino destaca a presença ubíqua 
das mídias na vida cotidiana da sociedade configurando-se como referência no espaço social.

São duas reflexões que se aproximam ao tratarem do assunto sob o aspecto tecnológico, isto é, reconhecem a dimensão técnica como fundamental nesta caminhada. Outra consensualidade, se é que podemos tratar desta forma, expande-se para uma dimensão social da tecnologia, perfazendo a relação entre mediações tecnológicas e necessidades dos indivíduos, numa profunda contaminação de modalidades comunicativas. Em outras palavras, a comunicação midiática se vê afetada pela "nova ordem comunicacional".

A base unidirecional de se comunicar por parte desses meios tradicionais foi então revisada para um modelo em que o público se torne participante em alguma medida por meio de compartilhamento, comentários, envio de material produzido pelos agentes no local dos acontecimentos, dentre outras formas.

\section{A crise venezuelana na cobertura internacional}

Os noticiários nacionais e as agências internacionais já acompanhavam a chamada crise humanitária da Venezuela. Entretanto, o fechamento das fronteiras entre a Venezuela e o Brasil voltou os olhos do mundo para esta região. Correspondentes de veículos brasileiros e de agências internacionais deslocaram-se para transmitir diretamente da fronteira brasileira em Pacaraima, no estado de Roraima, com Santa Elena de Uairém, município venezuelano da província de Bolívar, as atualizações diárias sobre a situação fronteiriça.

Trata-se de acontecimentos numa fronteira seca entre Brasil e Venezuela em que as cidades gêmeas convivem em mútua interdependência. A cidade venezuelana possui o atrativo da mineração de diamantes, ademais do combustível barato, e nela passam linhas de transmissão de energia elétrica responsável pelo abastecimento do estado de Roraima. Ela pode ser entendida como uma zona-tampão, regiões estratégicas em que o Estado restringe ou interdita o acesso à faixa e à zona de fronteira (parques naturais nacionais, áreas protegidas ou áreas de reserva - terras indígenas). Conforme levantamento de Edileuson Almeida e Ada Silveira (2015), as redes de comunicação estruturadas estão em território da Venezuela, com a presença de uma emissora de rádio com programação bilíngue. 
Ainda conforme Almeida e Silveira (2015), a $1^{\text {a }}$. Conferência Estadual de Comunicação de Roraima, convocada pelo Poder Legislativo Estadual em 2009 teve como tema "Comunicação: meios para a construção de direitos e de cidadania na era digital" contou com expressiva participação de profissionais e professores de jornalismo e mídia. Uma das mesas de debate abordou especificamente "A ausência de mídia na Região de Fronteira", registrando a situação de Pacaraima, onde não existia nenhum veículo de comunicação brasileiro. A situação daquele município proporcionou a veiculação de um documento de sua conferência municipal, constante de 12 pontos, dentre os quais se registraram: a reclamação por políticas públicas destinadas a democratizar os meios de comunicação e a promoção do direito à informação. Também constaram do documento a proposta de radiodifusão comunitária e telefonia pública, especialmente em áreas indígenas, a não cobrança de taxa de telefonia em discagem direta internacional (DDI) em áreas fronteiriças, o livre trânsito de profissionais de comunicação, a veiculação de conteúdos educativos em canal aberto em horário acessível à população.

É neste contexto de precariedade comunicativo-midiática que a crise política venezuelana passou a ser sentida e noticiada no local. Acentuada em janeiro de 2019 , quando Maduro tomou posse para um novo mandato de seis anos, sua legitimidade foi questionada pela oposição e por parte da comunidade internacional. Juan Guaidó presidente do Poder Legislativo, autoproclamou-se presidente encarregado por considerar que o líder chavista usurpa a Presidência.

$\mathrm{Na}$ análise da cobertura realizada, a cronologia da semana em referência (21 a 27 de fevereiro de 2019) pode ser observada no Quadro 1 a seguir:

Quadro 1: Noticiário dos sete primeiros dias da fronteira fechada

\begin{tabular}{|c|c|}
\hline Data & Titulo da matéria, veiculo, data e link \\
\hline \multirow{4}{*}{$\begin{array}{l}21 \\
\text { fev. } \\
2019\end{array}$} & $\begin{array}{l}\text { Maduro decide fechar fronteira com Brasil e ameaça fazer o mesmo com } \\
\text { Colômbia. Agência Reuters. } 21 \text { fev. } 2019 \text {. Disponivel em: } \\
\text { <http://twixar.me/clil } 23>\text { Acesso em: } 21 \text { fev. } 2019 \text {. }\end{array}$ \\
\hline & $\begin{array}{l}\text { Deputados ve nezuelanos viajam em três ônibus para fronteira com a } \\
\text { Colômbia. Agência Efe. } 21 \text { fev. } 2019 \text { Disponivel em: <http://twixar.m e/MnL23> } \\
\text { Acsso em: } 21 \text { fev. } 2019 \text {. }\end{array}$ \\
\hline & $\begin{array}{l}\text { Guaidó parte para a fronteira com Colôbia para reœber ajuda humanitária. } \\
\text { Agência E fe. } 21 \text { fev.2019. Disponivel em: <http://twixar.me/QW23>. Acesso } \\
\text { em: } 21 \text { fev. } 2019 \text {. }\end{array}$ \\
\hline & $\begin{array}{l}\text { Venezuela fecha fro nteira com o Brasil. Portal G1.21 fev. 2019. Disponivel } \\
\text { em: <http://twixar.me/6l/23>. Acesso em: } 21 \text { fev. } 2019 \text {. }\end{array}$ \\
\hline \multirow[t]{2}{*}{$\begin{array}{l}22 \text { fev. } \\
2019\end{array}$} & $\begin{array}{l}\text { Estamos morrendo de fome. O que dizem os venezuelanos que desafiam a } \\
\text { fro nteira fechada e fogem para o Brasil. Portal G1. } 22 \text { fev. } 2019 \text {. Disponivel } \\
\text { em: <http://twixar.me/CM } 23>\text { Acesso em: } 22 \text { fev. } 2019 \text {. }\end{array}$ \\
\hline & Guaidó exige abertura da fronteira da Venezuela $\infty \mathrm{m}$ o Brasil. Agência E \\
\hline
\end{tabular}




\begin{tabular}{|c|c|}
\hline & $\begin{array}{l}\text { Primeiro avião com ajuda humanitária para a Venezuela chega a Roraima. } \\
\text { Agência E fe. } 22 \text { fev. } 2019 \text {. Disponivel em: <http://twixar.me/rll 23> Acesso } \\
\text { em: } 22 \text { fev. } 2019 \text {. }\end{array}$ \\
\hline & $\begin{array}{l}\text { Primeiro avião com ajuda humnitária para a Venezuela chega a Roraima. EI } \\
\text { País. } 22 \text { fev. } 2019 \text {. Disponivel em: <http://twixar.m e/3Q23>Aœsso em: } 22 \\
\text { fev. } 2019 \text {. }\end{array}$ \\
\hline & $\begin{array}{l}\text { Rússia acusa EUA e OTAN de planejar entrega de armas para oposição } \\
\text { venezuelana. Agência Efe. } 22 \text { fev. } 2019 \text {. Disponivel em: } \\
\text { <http://twixar.me/6FH3> Acesso em: } 22 \text { fev. } 2019 \text {. }\end{array}$ \\
\hline \multirow[t]{6}{*}{$\begin{array}{l}23 \text { fev. } \\
2019\end{array}$} & $\begin{array}{l}\text { Caminhões com ajuda hum anitária do Brasil partem para a fronteira com } \\
\text { Venezuela. Agência E fe. } 23 \text { fev. } 2019 \text {. Disponivel em: } \\
\text { <http://twixar.me/2FH3> Acesso em } 23 \text { fev.2019. }\end{array}$ \\
\hline & $\begin{array}{l}\text { EUA advertem que Maduro não ficará impune após confrontos na fronteira. } \\
\text { Agência E fe. } 23 \text { fev. } 2019 \text {. Disponivel em: <http://twixar.me/kFH3> Acesso } \\
\text { em } 23 \text { fev. } 2019 \text {. }\end{array}$ \\
\hline & $\begin{array}{l}\text { Na fronteira da Venezuela com a Colômbia, distúrbios violentos e dezenas de deserçōes } \\
\text { chavistas. Internacional. EI País. } 23 \text { fev.2019. Disponivel em: } \\
\text { <http://twixa r.me/nLH3> Acesso em } 23 \text { fev.2019. }\end{array}$ \\
\hline & $\begin{array}{l}\text { Militares venezuelanos desertam em meio a tensão na fronteira. Portal G1. } \\
23 \text { fev. } 2019 \text {. Disponivel em: <http://twixar.me } / T L H 3>\text { Acesso em } 23 \\
\text { fev. } 2019 \text {. }\end{array}$ \\
\hline & $\begin{array}{l}\text { Nicolas Maduro rompe rela çaes dip lomáticas com Colômbia. Portal G1. } 23 \\
\text { fev. } 2019 \text {. Disponivel em: <http://twixar. me/GLH3> Acesso em } 23 \text { fev. } 2019 .\end{array}$ \\
\hline & $\begin{array}{l}\text { Venezuela ordena fechar a fronte ira com a Colômbia no Estado de Táchira. } \\
\text { E stadão. } 23 \text { fev. } 2019 \text {. Disponivel em: <http://twixar.me/dLH3> Acsso em } \\
23 \text { fev. } 2019 \text {. }\end{array}$ \\
\hline \multirow{6}{*}{$\begin{array}{l}24 \\
\text { fev. } \\
2019\end{array}$} & $\begin{array}{l}\text { Na fronte ira colombiana, ajuda hum anitária à Venezuela é recobida com gás } \\
\text { lacrim ogêneo e tiros. Agência Reuters. } 24 \text { fev. } 2019 \text {. Disponivel em: } \\
\text { <http://twixar.me/LLH3> Acesso em: } 24 \text { fev. } 2019 \text {. }\end{array}$ \\
\hline & $\begin{array}{l}\text { Colômbia fecha por dois dias a fronte ira com a Venezuela para avaliar } \\
\text { danos. Agência Efe. } 24 \text { fev. } 2019 \text {. Disponivel em: <http://twixar.m eNWLH3> } \\
\text { Acesso em } 24 \text { fev.2019. }\end{array}$ \\
\hline & $\begin{array}{l}\text { Distúrbios na fronteira entre Colômbia e Venezuela deixam } 285 \text { feridos. } \\
\text { Agência Efe. } 24 \text { fev. } 2019 \text {. Disponivel em: <http://twixar.m e/ZLH } 3>\text { Acsso } \\
\text { em } 24 \text { fev. } 2019 \text {. }\end{array}$ \\
\hline & $\begin{array}{l}\text { EUA destinam } 56 \text { milhões de dólares à Venezuela apesar da brutalidade de } \\
\text { Maduro. Agência E fe. } 24 \text { fev.2019. Disponivel em: }\langle\text { https://bit.ly/2NM } 4 \text { Tex }> \\
\text { Acesso em } 24 \text { fev. } 2019 \text {. }\end{array}$ \\
\hline & $\begin{array}{l}\text { Protagonismo de Trump na crise da Venezueb, uma áca de dos gumes para Guaidó. EI } \\
\text { País. } 24 \text { fev. } 2019 \text {. Disponivel em: <https://bitt. Iy/2TICXE d > Acesso em } 24 \\
\text { fev. } 2019 \text {. }\end{array}$ \\
\hline & $\begin{array}{l}\text { Sargentos venezuelanos desertam na fronteira com o Brasil. Agência E fe. } \\
24 \text { fev.2019. Disponivel em: <https://bit.ly/2IVcodu> Acesso em } 24 \text { fev. } 2019 \text {. }\end{array}$ \\
\hline $\begin{array}{l}25 \text { fev. } \\
2019\end{array}$ & $\begin{array}{l}\text { China critica a politização da entrega de ajuda a Ven ezuela e pede diálogo. } \\
\text { Agência Efe. } 25 \text { fev. } 2019 \text {. Disponivel em: }<\text { https://bit.ly/2SO zU ze }>\text { Acsso } \\
\text { em } 25 \text { fev. } 2019 \text {. }\end{array}$ \\
\hline
\end{tabular}

Revista Pauta Geral-Estudos em Jornalismo, Ponta Grossa, vol. 6, n. 1, p. 39-58, Jan/Jun, 2019. 


\begin{tabular}{|c|c|}
\hline & $\begin{array}{l}\text { EUA pedem reunião do Conselho de Segurança da ONU sobre a Venezuela. } \\
\text { Agência Efe. } 25 \text { fev. } 2019 \text {. Disponivel em: <htfips://bit.ly/2H kXdyE > Acesso } \\
\text { em } 25 \text { fev. } 2019 \text {. }\end{array}$ \\
\hline & $\begin{array}{l}\text { EUA sancionam quatro governadores vene zuelanos por bloqueio de ajuda. } \\
\text { Agência Efe. } 25 \text { fev.2019. Disponivel em: < https://bit.ly } / 2 \mathrm{ES} \text { YBH m > Acesso } \\
\text { em } 25 \text { fev. } 2019 \text {. }\end{array}$ \\
\hline & $\begin{array}{l}\text { Guaidó diz que ser permissivo com Maduro a meaça a democracia na } \\
\text { América. Agência E fe. } 25 \text { fev.2019. Disponivel em: < https://bit.ly/2 Hkqmdf > } \\
\text { Acsso em } 25 \text { fev. } 2019 \text {. }\end{array}$ \\
\hline & $\begin{array}{l}\text { Grupo de Lima rejeita ação militar na Venezuela apesar da pressão } \\
\text { am ericana. Folha S. Paulo. } 25 \text { fev. } 2019 \text {. Disponivel em: } \\
\text { <https://bit.ly/2T fNkIT> Acesso em } 25 \text { fev. } 2019 .\end{array}$ \\
\hline & $\begin{array}{l}\text { Grupo de Lima reitera que a transção na Venezueb deve ser paófica. El País. } 25 \\
\text { fev.2019. Disponivel em: <https://bit.ly/2H78Zgl > Acesso em } 25 \text { fev. } 2019 \text {. }\end{array}$ \\
\hline & $\begin{array}{l}\text { E mbates na fronteira com a Venezu ela colo cam Brasil numa encruzilhada } \\
\text { diplom ática. EI País. } 25 \text { fev.2019. Disponivel em: <https://bit.ly/2VovqkX> } \\
\text { Acsso em } 25 \text { fev.2019. }\end{array}$ \\
\hline & $\begin{array}{l}\text { Mouräo diz que saida de Maduro da Ven ezuela seria solução pacifica para } 0 \\
\text { pais. Globo News. } 25 \text { fev. } 2019 \text {. Disponivel em: <https://glo.bo/2WKboTrs } \\
\text { Aœsso em } 25 \text { fev. } 2019 \text {. }\end{array}$ \\
\hline \multirow[t]{3}{*}{$\begin{array}{l}26 \text { fev. } \\
2019\end{array}$} & $\begin{array}{l}\text { EUA negam acusação russa de que estariam preparando intervenção na } \\
\text { Venezuela. Agência Reuters. } 26 \text { fev. } 2019 \text {. Disponivel em: } \\
\text { <https://bit.ly/2Hot8yt > Acesso em } 26 \text { fev.2019. }\end{array}$ \\
\hline & $\begin{array}{l}\text { Quién está com prando petroleo vene zolano tras las sanciones. EI Nacional. } \\
26 \text { fev. } 2019 \text {. Disponivel em: <https://bit.ly/2VpbEWr }>\text { Acesso em } 26 \\
\text { fev. } 2019 \text {. }\end{array}$ \\
\hline & $\begin{array}{l}\text { Roraima pequeña ciudad bra sileña que vive Ve nezuela. EI Nacional. } 26 \\
\text { fev.2019. Disponivel em: }\langle\text { https://bit.ly/2SZE nV2 }>\text { Acesso em } 26 \text { fev.2019. }\end{array}$ \\
\hline \multirow{6}{*}{$\begin{array}{l}27 \\
\text { fev. } \\
2019\end{array}$} & $\begin{array}{l}\text { Maduro e Trump devem se reunir para "achar interesses em comum", diz } \\
\text { ministro venezue lano. Agência Reuters. } 27 \text { fev. } 2019 \text {. Disponivel em: } \\
\text { <https://bit.ly/2TnpJHn> Acesso em } 27 \text { fev. } 2019 \text {. }\end{array}$ \\
\hline & $\begin{array}{l}\text { A frágil economia da fronteira Brasil-Venezuela já sofre o impado do } \\
\text { fechamento. EI País. } 26 \text { fev.2019. Disponivel em: }\langle\text { https://bit.ly/2H } 7 \mathrm{LN} \text { y8 }> \\
\text { Acesso em } 26 \text { fev.2019. }\end{array}$ \\
\hline & $\begin{array}{l}\text { Colômbia pede que ONU tome ação contra crise na Venezuela. Agência } \\
\text { Reuters. } 27 \text { fev. } 2019 \text {. Disponivel em: <https://bit.ly/2H5Mrhl z> Acesso em } \\
27 \text { fev. } 2019 \text {. }\end{array}$ \\
\hline & $\begin{array}{l}\text { Guaidó diz que em breve retornará a Venezu ela para exercer suas funçes. } \\
\text { Agência E fe. } 27 \text { fev.2019. Disponivel em: http s://bit.ly/2XBPbHo> Acesso } \\
\text { em } 27 \text { fev.2019. }\end{array}$ \\
\hline & $\begin{array}{l}\text { EUA pressionam na ONU para que Maduro renuncie de maneira pacifica. EI } \\
\text { País. } 27 \text { fev. } 2019 \text {. Disponivel em: <https://bit.ly/2tRO } 88 \mathrm{C}>\text { Aœsso em } 27 \\
\text { fev. } 2019 \text {. }\end{array}$ \\
\hline & $\begin{array}{l}\text { Pelo menos } 85 \text { militares ve nezuelanos desertaram na Colômbina nas últim as } \\
24 \text { horas. Agência E fe. } 27 \text { fev. } 2019 \text {. Disponivel em: <https://bit.ly/2H6pXfws } \\
\text { Acesso em } 27 \text { fev. } 2019 \text {. }\end{array}$ \\
\hline
\end{tabular}

Revista Pauta Geral-Estudos em Jornalismo, Ponta Grossa, vol. 6, n. 1, p. 39-58, Jan/Jun, 2019. 
Fonte: elaboração dos autores com base nos sites referidos.

O histórico levantado dá conta de que o Presidente Maduro determinou na quintafeira (21/02/2019) o fechamento da fronteira da Venezuela com o Brasil por tempo indeterminado. A medida aconteceu após Guaidó anunciar que a ajuda humanitária dos Estados Unidos seria enviada pelas fronteiras venezuelanas. Os argumentos governistas eram de que a ajuda seria uma forma de encobrir uma intervenção militar na Venezuela e derrubar o governo. No mesmo dia, Maduro também fechou as fronteiras marítimas e de voos com as ilhas de Aruba, Bonaire e Curaçao, integrantes das Antilhas Holandesas no Mar do Caribe. O líder chavista também declarou intenção de fechar a fronteira com a Colômbia, já que Guaidó havia iniciado uma viagem para forçar a entrada dos alimentos e medicamentos pela fronteira colombiana.

No primeiro dia de fronteiras fechadas, alguns venezuelanos tentaram cruzar para o Brasil por rotas alternativas na tentativa de sair do país, alguns alegam estarem passando fome. Já do outro lado da fronteira, um grupo de manifestantes indígenas tentou barrar pacificamente a passagem para as terras brasileiras das Forças Armadas Venezuelanas que pretendia bloquear o acesso às fronteiras. Os soldados entraram no Brasil e abriram fogo contra os civis, e pelo menos quinze pessoas ficaram feridas e uma morte foi confirmada. Frente a essa atitude, o líder Guaidó pediu pela abertura das fronteiras com o Brasil em um decreto presidencial no Twitter, mas o pedido não foi atendido pelas Forças Armadas Venezuelanas, que em grande maioria ainda apoiam o governo Maduro.

No mesmo dia de conflito na fronteira brasileira, o primeiro avião da Força Aérea Brasileira de ajuda humanitária aterrissou na base militar de Boa Vista (RR) com 22 toneladas de leite em pó e 500 kits de primeiros socorros, e o presidente Jair Bolsonaro garantiu que a ajuda humanitária estava mantida e seria enviada no sábado. $O$ vicepresidente Hamilton Mourão viajou para Bogotá, capital colombiana, para encontrar outros líderes dos países latino-americanos.

Em contrapartida, a Rússia, como aliada chavista, acusou os EUA e a OTAN, organização militar intergovernamental baseada no Tratado do Atlântico Norte, de estarem comprando grandes lotes de armas e munições na Europa para repassarem aos opositores do governo Maduro para intervirem no sábado, dia que os países iriam entrar pelas fronteiras com a ajuda humanitária. 
Na sexta-feira também começou o festival beneficente Venezuela Aid Live, que foi promovido pelo empresário britânico Richard Branson a ser realizado no lado colombiano da ponte de Tienditas, uma das três passagens que ligam a Venezuela à Colômbia. Os shows contavam com grandes nomes da música latina como Alejandro Sanz, Juanes, e LuisFonsi. A finalidade do evento era demonstrar apoio a Guaidó e arrecadar 100 milhões de dólares em 60 dias para destinar à ajuda humanitária na Venezuela. Do outro lado da fronteira aconteceram outros shows promovidos por Maduro em apoio ao governo com o nome de HandsOff, interpretado como "tire as mãos da Venezuela".

Mesmo com as fronteiras colombianas fechadas, Guaidó conseguiu cruzá-las por uma rota alternativa e se encontrou com os outros líderes do Grupo Lima, incluindo o vicepresidente brasileiro Hamilton Mourão. Guaidó aproveitou o festival Venezuela Aid Live para se pronunciar publicamente e pedir a Maduro que aceitasse a ajuda humanitária armazenada na fronteira colombiana.

Alguns apoiadores do presidente interino foram até a fronteira protestar e forçar a entrada dos mantimentos no país. A tentativa acabou em um embate com as Forças Armadas Venezuelanas com o uso de força bruta para impedir os civis. Esse conflito também fez com que muitos militares deixassem de apoiar o governo Maduro e cruzassem a fronteira para a Colômbia pedindo refúgio no país. Os soldados relataram que o pedido de repressão aos manifestantes era muito forte, e defendia violência ou até morte. Segundo o jornal El País, o número de militares venezuelanos a deixarem o exército chegou a 60 pessoas no sábado.

Devido aos conflitos acontecidos em uma das fronteiras com a Venezuela, a Colômbia decidiu fechar todas as fronteiras por pelo menos dois dias. O embate na fronteira deixou 285 feridos, dentre eles 37 foram hospitalizados devido ao uso da violência com tiros e gás lacrimogêneo dos militares venezuelanos contra os civis.

Guaidó se pronunciou via Twitter pedindo o apoio e a ajuda da comunidade internacional para a Venezuela. O presidente Donald Trump se pronunciou e disse que "apesar da brutalidade de Maduro" iria enviar US\$ 56 milhões para ajuda humanitária na Venezuela, mas também ressaltou que o governo Maduro não ficará impune pelos crimes cometidos pelas Forças Armadas da Venezuela em obediência a ordens do presidente.

$\mathrm{Na}$ segunda-feira representantes dos países que compõem o Grupo de Lima se reuniram em Bogotá, Colômbia, para tentar definir estratégias contra o governo de Maduro. Embora Guaidó levantasse a possibilidade de uma intervenção militar na Venezuela, como 2019. 
única saída, os países do bloco reafirmaram que a transição para a democracia deveria acontecer de forma pacífica pelos próprios venezuelanos, com apoio de meios políticos e diplomáticos e sem o uso de força. Essa foi uma resposta tanto a Guaidó, quanto ao vicepresidente norte-americano Mike Pense.

O vice-presidente brasileiro reafirmou o papel pacífico e diplomático que o Brasil tem há anos e rejeitou a possibilidade de deixar que os EUA utilizem o território brasileiro para uma operação militar na Venezuela. Os países também reiteraram que os EUA não fazem parte do Grupo de Lima, e que apesar de estar dialogando com o país, a decisão do bloco é resolvida entre os mesmos.

Os EUA sancionaram quatro governadores venezuelanos por bloquearem ajuda humanitária, os que são responsáveis pelas cidades de fronteira e porto da Venezuela. Com essa medida ficam congelados os ativos sob jurisdição americana, e fica proibida a realização de transações financeiras por parte de entidades norte-americanas. O país também pediu à Organização das Nações Unidas uma reunião para debater mais uma vez a situação do país latino-americano.

No mesmo dia, a China se pronunciou quanto à crise e afirmou que os conflitos gerados em torno da ajuda humanitária não beneficiavam ninguém, e que deveria existir o diálogo com Maduro para a permissão de entrada de ajuda, sem a imposição. Além disso, reafirmou a necessidade de um diálogo diplomático e criticou a politização da ajuda humanitária.

A crise na Venezuela se deu em grande parte pela exportação de petróleo, que é a principal economia do país. O maior comprador era os Estados Unidos, que aplicou várias sanções ao país, na intenção de derrubar o governo Maduro. O país depositava o dinheiro da compra do petróleo em uma conta a qual a Venezuela não tinha acesso, são quase 30 milhões retidos. Frente a isso, Maduro cortou a relação comercial com os Estados Unidos e agora o grande comprador tornou-se a Índia, e também a China. Apesar disso, a economia ainda não sobrevive bem sem a exportação para o país norte-americano.

O impacto econômico em Pacaraima é o que está enfatizado na cobertura, pois os brasileiros abasteciam mais barato nos postos de gasolina venezuelanos e na cidade brasileira não há postos de combustíveis.

Os Estados Unidos negaram a acusação feita pela Rússia de que estariam planejando uma intervenção militar na Venezuela. Na quarta-feira durante a reunião no Conselho de Direitos Humanos da ONU, os Estados Unidos pediram pelo direito de eleições 2019. 
pacíficas e credíveis na Venezuela. Na ocasião, a Colômbia fez pedido para que os casos de violência na fronteira fossem analisados. Já o chanceler venezuelano sugeriu que Maduro e Trump deveriam se encontrar para um diálogo direto.

O acompanhamento do noticiário relatado no "Quadro 1" permite considerar o quanto é difícil compreender o que tem sido denominado como crise humanitária na Venezuela, pois envolve muitas relações diplomáticas. Entretanto, uma breve análise dos jornais que são opositores do governo venezuelano, como o El Nacional (que tem até editorias no jornal sobre a diáspora e presos políticos), permite perceber que eles não tratam os acontecimentos da mesma forma que estão tratando os jornais brasileiros. Neste jornal a crise é tratada como política e econômica, mas não como algo beirando a miséria, como muitos jornais brasileiros tratam.

Poucos dos noticiários analisados nestes sete dias aprofundaram o histórico da crise econômica, e nem mesmo entrevistaram venezuelanos para entender a perspectiva de quem está lá. Neste sentido, o jornal Folha de S. Paulo produz diariamente o podcast "Café da Manhã", sobre os assuntos mais falados no dia anterior, e na edição do dia 25 de fevereiro de 2019, tratou sobre a crise venezuelana (FOLHA, 2019). O material aborda diferentes pontos de vista, com relatos de jornalistas que estão na fronteira.

\section{Análise do Portal G1}

Para aprofundar a cobertura da crise reduziu-se o recorte temporal do material jornalístico publicado no portal de notícias G1/Região/Norte/Roraima ao período compreendido entre os dias 22 e 24 de fevereiro de 2019. O portal foi escolhido por ser um veículo jornalístico de envergadura nacional, com base regional e local. A coleta do material decorreu da observação atenta no período, somando um total de 35 notícias, as quais estavam distribuídas da seguinte forma: 14 publicadas no dia 22; 12 publicadas no dia 23 e 9 publicadas no dia 24. As matérias estudadas estão referidas no Quadro 2 a seguir:

Quadro 2: Matérias destacadas da cobertura entre 22-23 de fevereiro no G1 


\begin{tabular}{|c|c|}
\hline \multirow{4}{*}{$\begin{array}{l}22 \\
\text { fev. } \\
2019\end{array}$} & $\begin{array}{l}\text { Avião com ajuda hum anitária para a Venezu ela chega a Boa Vista. Portal G1. } \\
22 \text { fev. } 2019 \text {. Disponivel em: <https://glo.bo/2U n kmZ >. Acesso em: } 22 \text { fev. } \\
2019 \text {. }\end{array}$ \\
\hline & $\begin{array}{l}\text { Bloqueio e confronto com morte elevam a tensão na fronteira entre Brasil e } \\
\text { Venezu ela. Portal G1. } 22 \text { fev. } 2019 \text {. Disponivel em: }\langle\text { https://glo.bo/2BOyn6V }\rangle \text {. } \\
\text { Acesso em: } 22 \text { fev. } 2019 \text {. }\end{array}$ \\
\hline & $\begin{array}{l}\text { Fechamento da fronteira não impede totalm ente a passagem entre Brasil e } \\
\text { Venezu ela. Portal G1. } 22 \text { fev. } 2019 \text {. Disponivel em: } \\
\text { <https://glo.bo/2EFAm Lu>. Acesso em: } 22 \text { fev. } 2019 \text {. }\end{array}$ \\
\hline & $\begin{array}{l}\text { Fronteira com a Venezuela em Roraima segue fechada na manhã desta sexta- } \\
\text { feira. Portal G1. } 22 \text { fev. } 2019 \text {. Disponivel em: <https://glo.bo/2U1DXK5> } \\
\text { Acesso em: } 22 \text { fev. } 2019 \text {. }\end{array}$ \\
\hline \multirow{2}{*}{$\begin{array}{l}23 \\
\text { fev. } \\
2019\end{array}$} & $\begin{array}{l}\text { Ministro faz a pelo para Venezuela abrir fronteira para permitir ingresso de } \\
\text { ajuda huma nitäria. Portal G1. } 23 \text { fev. } 2019 \text {. Disponivel em: } \\
<\text { https://glo.bo/2UnJQ4p>. Acesso em: } 23 \text { fev. } 2019 \text {. }\end{array}$ \\
\hline & $\begin{array}{l}\text { Venezu elanos protestam em Paca raima em favor de ajuda hum anitária do } \\
\text { Brasil. Portal G1. } 22 \text { fev. 2019. Disponivel em: <https://glo. bo/2GYARTy }\rangle \text {. } \\
\text { Acesso em: } 23 \text { fev. } 2019 \text {. }\end{array}$ \\
\hline
\end{tabular}

Fonte: Elaboração dos autores com base nos sites referidos.

A opção pelo filtro regional/local deu-se em razão da proximidade com o local dos acontecimentos. No entanto, a mesma cobertura pela via regional/local foi refletida na página principal do portal, expandindo fronteiras geográficas e se tornando dessa forma tema internacional.

Mesmo os acontecimentos estando presentes na pauta há meses, o recorte de tempo capturou os dias em questão que foram o epicentro da crise, com fechamento das fronteiras com muita manifestação de populares e atravessamentos políticos de nível globalizado.

A metodologia de trabalho partindo de um levantamento documental buscou identificar o número de notícias publicadas no ponto alto da crise, pois na sequência, a partir do dia 25 de fevereiro, a cobertura teve continuidade e porque nos limites de produção deste estudo é possível reconhecer uma razoável atuação da cobertura internacional marcada por uma significativa midiatização do tema e da região, que ganharam ampla visibilidade. Embora o mote principal do estudo seja verificar o volume da produção jornalística no recorte temporal, todas as notícias coletadas foram lidas e algumas destacadas para descrição e análise.

A primeira notícia publicada no dia 22 aconteceu às 8 h02 horário de Brasília. Segundo o texto do jornalista (Chaves, 2019) "Fronteira com a Venezuela em Roraima segue fechada nesta sexta-feira", o enquadramento é fixado na proibição/bloqueio para 2019. 
atravessar a fronteira por ordem do presidente Maduro e a intensa fiscalização do exército venezuelano. A notícia é composta por várias fotos, inclusive três delas creditadas a Ricardo Moraes da Agência Reuters. Este ponto da cobertura indica para aspectos que foram discorridos neste artigo quando foi abordada a interação das agências internacionais de notícias na produção de conteúdo, visando difusão internacional.

No mesmo dia, às 8h10 no horário de Brasília houve atualização no portal com notícia dando continuidade na abordagem do fechamento da fronteira e o texto busca explicar o porquê. No decorrer da matéria há sinalização da crise política, envolvendo Venezuela, Estados Unidos, além de Brasil e de outros países, com impedimento por parte do governo de Maduro da entrada de ajuda humanitária na Venezuela. O trecho do texto registra:

Maduro determinou o fechamento para tentar barrar a ajuda humanitária oferecida pelos EUA e por países vizinhos, incluindo o Brasil, após pedido do autoproclamado presidente interino Juan Guaidó. Maduro vê a oferta dessa ajuda como uma interferência externa na política do país. [CHAVES \& COSTA, Fechamento da fronteira não impede totalmente a passagem entre Brasil e Venezuela, 2019].

A reportagem apresenta ainda a fotografia de um vídeo com identificação da Rede Globo de Televisão que dá a impressão de ser um material veiculado em programas da emissora, mas que não há uma clara identificação da origem. Outro aspecto que chama a atenção é a proximidade entre uma publicação e outra, às 8 h02 e 8h10, passando a ideia da veiculação da notícia em capítulos de modo a reter a audiência.

Às 11 h50 ainda do dia 22, mais uma notícia foi publicada agora tendo como enquadramento a ajuda humanitária (alimentos e medicamentos) vinda em aeronave da Força Aérea Brasileira. A matéria apresenta um trecho a destacar e que traz a sinalização de crise globalizada, demonstrando claramente uma ampla polarização de regimes políticos. O trecho registra: "A Rússia e a China, que apoiam o regime de Maduro, afirmaram que a entrada de ajuda humanitária na Venezuela pode criar conflitos" [G1, Avião com ajuda humanitária chega a Boa Vista, 2019]. A matéria é ilustrada por fotografia creditada a Nelson Almeida para Agence France Presse (AFP).

O Portal G1 seguiu com atualizações praticamente de hora em hora até o início da noite do dia 22, com notícias agendando para o bloqueio por ordem do presidente Maduro, 
o número de feridos, os conflitos envolvendo militares e indígenas, venezuelanos passando fome e a ajuda humanitária como estopim da crise.

A última atualização no dia 22 ocorreu às $21 \mathrm{~h} 32$, um texto publicado na página principal do portal na Editoria Mundo. Título e gravata da reportagem focam no bloqueio, na temperatura elevada do conflito e na determinação do presidente venezuelano no fechamento da fronteira para impedir a entrada de ajuda humanitária [G1, Bloqueio e confronto com morte elevam a tensão na fronteira entre Brasil e Venezuela, 2019].

A primeira notícia veiculada no dia 23 foi às 8 h06, dando conta de que a fronteira permanecia fechada e que os caminhões com ajuda humanitária brasileira haviam chegado à cidade fronteiriça de Pacaraima. $O$ texto traz ainda uma retranca dando destaque para 0 fechamento da Ponte Simón Bolívar entre Venezuela e Colômbia.

Próximo ao horário do almoço, as atualizações no portal deram destaque para o pronunciamento do chanceler brasileiro, ministro Ernesto Araújo, feito ao vivo e transmitido por diversos telejornais. Nesta ocasião, também se pronunciou a representante do governo interino da Venezuela, María Teresa Belandria.

Às 12h06, quando houve a próxima atualização no portal, foi possível identificar uma cobertura marcada por convergências de veículos noticiosos. A identificação ocorre provavelmente do enquadramento da notícia que passa a concentrar-se no conflito na fronteira entre Venezuela e Colômbia:

$\mathrm{Na}$ fronteira com a Colômbia, uma carreta com ajuda comunitária foi saqueada e incendiada durante o confronto entre oposição e integrantes das forças de segurança venezuelanas, de acordo com informações da agência Reuters. [G1, Ministro faz apelo para Venezuela abrir fronteira para permitir ingresso de ajuda humanitária, 2019].

Muitas fotografias utilizadas na reportagem são da mesma agência. Há registros em vídeo praticamente de dentro dos acontecimentos e que foram distribuídos por agência internacional, além de material distribuído por outros canais, como o VTV do governo venezuelano e material fotográfico de arquivo pessoal de populares. É um forte de registro de convergência midiática e cobertura midiatizada do acontecimento.

Os textos publicados no dia 24 de fevereiro de 2019 tiveram como enfoque principal as deserções de militares do exército venezuelano que buscaram refúgio no Brasil e as ações políticas do governo brasileiro para pressionar o governo de Nicolás Maduro. 


\section{Considerações finais}

O estudo foi realizado num momento em que seu objeto de análise está em curso: a cobertura jornalística na fronteira entre Brasil e Venezuela e também da Venezuela e Colômbia. Buscou-se apreender o volume de notícias disponível no Brasil dentro de um período específico, e sobre uma agenda de visibilidade internacional.

Os episódios envolvendo a crise política, econômica e social na Venezuela, sobretudo a semana do fechamento de fronteiras e no período compreendido entre os dias 22 a 24 de fevereiro de 2019, registra um momento de cobertura jornalística intensa e midiatizada.

A cobertura dos acontecimentos, desde os momentos mais críticos da crise, vem sendo realizada pela mídia de referência, que possui envergadura nacional e internacional, junto a meios jornalísticos regionais e locais, bem como pela efetiva participação do público in loco, todos fazendo circular mensagens e representações do contexto, segundo visões e enquadramentos próprios.

Nos dias 22-23 de fevereiro, considerados como o epicentro da crise, foi possível identificar no ambiente da internet, nos portais e sites de notícias do Brasil e do mundo, a cobertura sendo realizada. Emissoras de televisão e rádio, jornais impressos de circulação nacional, regional e local mandaram para a região dos acontecimentos enviados especiais para participarem de uma cobertura de escala internacional. Cada qual com seus interesses editoriais, a midiatização desta fronteira ganhou visibilidade em todo o mundo, especialmente pelas histórias de interesse humano que dali foram reportadas.

A midiatização dos acontecimentos por parte dos veículos de imprensa e indivíduos pode produzir diferentes olhares sobre a região, dando conta de uma cobertura internacional ainda mais abrangente e conectada por meio de redes.

Confirma-se com o breve levantamento realizado que o jornalismo de modo geral e em específico a prática internacional ajuda a estruturar os acontecimentos sobre determinada realidade. Diante das possibilidades que a convergência digital apresenta para a produção e difusão de conteúdos instantâneos, a cobertura internacional também se modificou, sendo observado um grande volume de publicações e atualizações constantes sobre um tema e seus desdobramentos. O ambiente midiatizado corrobora para esta nova forma de operação jornalística, colocando no centro da produção não somente aparatos técnicos, mas revelando a dimensão social das tecnologias comunicacionais. 


\section{ESTUDOS EM JORNALISMO}

É possível, assim, contrastar mesmo num ambiente de mídia concentrada como o Brasil, a diversidade de pontos de vista que podem ser veiculados. Passados 150 anos do final da guerra da Tríplice aliança com o Paraguai, a possibilidade e voltar a ter conflito com um vizinho, mobiliza a atenção da mídia de referência. Pouca atenção, no entanto, é dada à posição dos parceiros da Venezuela, como Rússia e China, e ainda menos a Cuba, no balanço do noticiário levantado. Fica explícita a adesão da mídia de referência brasileira aos pontos de vista expressos pelos Estados Unidos e respaldados pelo atual governo federal brasileiro.

\section{Referências}

ALMEIDA, Edileuson S.; SILVEIRA, Ada C. M. Comunidades de Comunicação. Nação e fronteiras do (des) encontro. Textos e Debates (UFRR). v.2, p.321 - 333, 2015.

BOMFIM, I. E. Latinidade: a América Latina pelas páginas de Veja e Carta Capital.

Biblioteca On-line de Ciências da Comunicação. 2006, p. 1-18. Disponível em: http://www.bocc.ubi.pt/pag/bomfim-ivan-latinidade.pdf. Acesso em: 26 fev. 2019.

BOMFIM, Ivan; MÜLLER, Karla M. Aiatolás atômicos: a cobertura das negociações Brasil e Irã pelo portal VEJA.com. Revista Intexto. Porto Alegre, ํo. 28, julho 2013, p.81-99. Disponível em: https://seer.ufrgs.br/intexto/article/view/41163. Acesso em 27 fev.2019

BRAGA, José L. Circuitos versus campos sociais. In: MATTOS, Maria Ângela; JANOTTI JUNIOR, Jeder; JACKS, Nilda (orgs.). Mediação \& Midiatização. Salvador/Brasília: EdUBa/Compós, 2012. p. 31-52. Disponível em:

https://static.scielo.org/scielobooks/k64dr/pdf/mattos-9788523212056.pdf. Acesso em: 3 mar. 2019.

CHAVES, Alan. Fronteira com a Venezuela em Roraima segue fechada na manhã desta sexta-feira. Portal G1. Disponível em:

https://g1.globo.com/rr/roraima/noticia/2019/02/22/fronteira-com-a-venezuela-em-roraimasegue-fechada-na-manha-desta-sexta-feira-apos-ordem-de-maduro.ghtml. Acesso em: 22 fev. 2019.

CHAVES, Alan; COSTA, Emily. Fechamento da fronteira não impede totalmente a passagem entre Brasil e Venezuela. Portal G1. Disponível em https://g1.globo.com/rr/roraima/noticia/2019/02/22/fechamento-da-fronteira-nao-impedetotalmente-a-passagem-entre-brasil-e-venezuela-entenda.ghtml. Acesso em: 22 fev. 2019.

FOLHA DE S.PAULO. Café da Manhã. 26 fev.2019. Disponível em: encurtador.com.br/BEY57. Acesso em 27 fev.2019.

HOHENBERG, John. A Grande Matéria: Washington, as Nações Unidas, o Mundo. In: ELHAJJI, Mohammed; AGUIAR, Pedro (org.). Jornalismo Internacional. Rio de Janeiro, 2008, p. 27- 40. Disponível em:

Revista Pauta Geral-Estudos em Jornalismo, Ponta Grossa, vol. 6, n. 1, p. 39-58, Jan/Jun, 2019. 
https://www.academia.edu/3221207/Apostila_de_Jornalismo_Internacional_ECO_UFRJ_2 008.2. Acesso em: 25 fev. 2019.

MARTINO, Luis M. S. Mediação e midiatização da religião em suas articulações teóricas e práticas: um levantamento de hipóteses e problemáticas. In: MATTOS, Maria Ângela;

JANOTTI JUNIOR, Jeder; JACKS, Nilda (orgs.). Mediação \& Midiatização.

Salvador/Brasília: EdUFBa/Compós, 2012, p. 219-244 Disponível em:

https://static.scielo.org/scielobooks/k64dr/pdf/mattos-9788523212056.pdf. Acesso em: 3

mar. 2019.

MONTEROS, Guilhermo G. E. Jornalismo internacional, correspondentes e testemunhos. In: ELHAJJI, Mohammed; AGUIAR, Pedro (org.). Jornalismo Internacional. Rio de Janeiro, 2008, p. 51- 56. Disponível em:

https://www.academia.edu/3221207/Apostila_de_Jornalismo_Internacional_ECO_UFRJ_2 008.2.Acesso em: 25 fev. 2019.

ROSSI, Clóvis. A Batalha no Mundo: Fluxo de Informação e Pauta Internacional. In: ELHAJJI, Mohammed; AGUIAR, Pedro (org.). Jornalismo Internacional - ECO/UFRJ. Rio de Janeiro, 2008, p. 14-16. Disponível em:

https://www.academia.edu/3221207/Apostila_de_Jornalismo_Internacional_ECO_UFRJ_2 008.2. Acesso em: 25 fev. 2019.

Recebido em: 07/03/2019.

Publicado em: 23/07/2019.

Revista Pauta Geral-Estudos em Jornalismo, Ponta Grossa, vol. 6, n. 1, p. 39-58, Jan/Jun, 2019. 